$\xi=-1$

\title{
Study on Time and Resource Management in Construction Projects Using MS Project
}

\author{
T.Subramani $^{1 *}$, T.M.Karthick ${ }^{2}$ \\ $1^{*}$ Managing Director, Priyanka Associates (Civil Engineers and Valuers), Salem, TamilNadu, India. \\ ${ }^{2}$ Design Engineer, Indo Builders ( Civil Engineers and Valuers), Dharmapuri, TamilNadu, India. \\ "Corresponding author: E-mail: tsmcivil2007@gmail.com
}

\begin{abstract}
This construction project study about excessive stake endeavor aiming at time certain programmed performance goal. Except combine resources are deliberate and procured, no activity may be completed in line with a pre fixed time table. Project managers ought to take complicated choices under exceptional scheduling desires and below situations of uncertainty that every so often expand past assignment intervals. Our project study offers with useful resource scheduling for a quick track project with constrained intervals. The learning has been executed in stages. Inside the first segment, with the useful resource of MS PROJECT software task time table for numerous activities for the development of a business constructing become prepared. Finally, requirements of sources had been attributed to the activities primarily depend on Standard Schedule Rates. The considered necessary necessity information collected from the designated drawings and triumphing site online situations. The analysis was completed with the aid of useful resource leveling for diverse activities by way of reducing resources with accelerated length to observe the time-cost implications.
\end{abstract}

Keywords: Time, Resource, Management, Construction and MS Project.

\section{Introduction}

Materials management capabilities encompass "material requirement planning and material take ox vendor evaluation and selection, purchasing, expenditure, shipping, material receiving, warehousing and inventory, and material distribution". This is worried with the planning and controlling system to ensure that the proper satisfactory and quantity of substances and mounted gadget are appropriately specified in a timely manner, received at affordable price and are to be had whilst needed. The management of materials need to be considered from the phases of the development technique and at some stage in the development length. Normally, creation substances are cumbersome, costly and are supplied in huge quantities to creation web sites. Therefore, there's a need for an high-quality management system for handling materials.

\subsection{Materials Management on Construction Projects}

The construction industry is the maximum good sized industry within the economic system and the hit degree with crowning glory within time, budget, accordance with specification and pleasure of stakeholders. Construction projects are complicated, with many agencies concerned which includes customers or owners, architects, engineers, contractors, suppliers and vendors. This consists of the heterogeneous and frequently complicated process of manufacturing precise, large and immovable merchandise with a deliver of the assets (cash, equipment, material, and hard work). As projects develop in scale and complexity, materials management becomes extra tough, often requiring the usage of suitable equipment and strategies to make sure, amongst different matters, that substances are added on time, stock ranges are nicely controlled, the development schedule is not compromised, and that wastage is minimized.

Materials management is mainly difficult for big and complicated tasks, where sophisticated equipment and techniques are important. The management of Materials in complicated production initiatives needs good enough attention due to the diverse elements involved and the importance of the Project. furthermore, the implementation of suitable ICT may want to facilitate new management processes for complex initiatives. as an example, the potential of rising technology along with wi-fi technology and tagging technologies should have a sturdy effect on substances management processes in the destiny. The unsuitable dealing with and control of substances on creation sites has the capacity to critically abate undertaking overall performance. The end result of fallacious coping with and handling substances on web site at some stage in creation process will have an impact on the overall assignment cost, time and the exceptional. The fees of substances control may variety from 30$80 \%$ of the total construction expenses depending on the sort of construction.

\subsection{Objective}

To optimize the project period i.e., to develop the total schedule to minimize the total time by minimizing workforce and equipment so as to minimize total cost of the project. To optimize use of the available construction workforce and develop a schedule to use it for other similar type of projects. 


\section{Methodology}

Fig. 1 shows the methodology of this study.

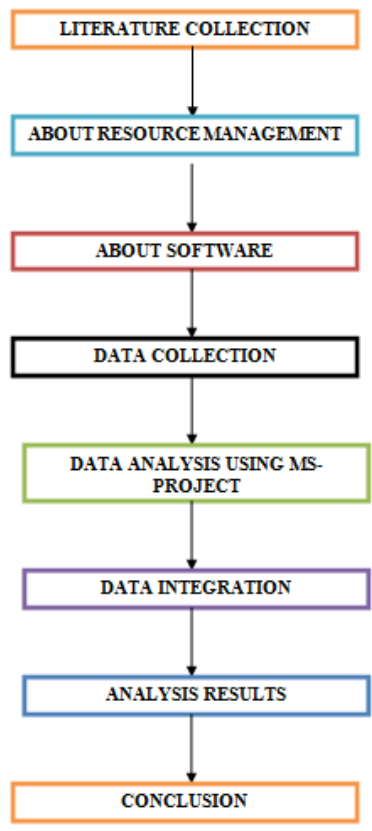

Fig.1: Methodology

\section{About Software}

It is designed to help a task manager in growing a plan, assigning assets to responsibilities, tracking development, handling the finances, and studying workloads. Undertaking creates budgets based on undertaking paintings and aid quotes. Resource definitions (humans, system and substances) can be shared between projects the usage of a shared resource pool. Every resource could have its very own calendar, which defines what days and shifts a useful resource is available.

Every useful resource can be assigned to multiple responsibilities in multiple plans and every assignment can be assigned more than one assets, and the utility schedules Project work based at the useful resource availability as described inside the useful resource calendars. All assets can be described in label without restrict. Therefore, it can't decide how many finished products may be produced with a given quantity of raw materials.

\section{Material Management}

Materials management is an important feature that improves productivity in production projects. Hence, the green use and management of material have an critical affect on a organization's income and might avoid postpone in production. for you to better apprehend materials control the subsequent strategies are discussed: making plans, procurement, logistics, dealing with, stock and waste manage. planning: Materials planning includes quantifying, ordering and scheduling. it's miles pressured that planning is mainly great in terms of growing productivity, income, and facilitating the timely of completion of construction projects.

\subsection{Materials Management Problems}

It is gathered collected that contemporary manual substances management practices and control tactics are unsatisfactory as they're hard work extensive, erroneous and error susceptible. The implication leads to waste and surplus of materials, delays, lower in productivity and shortage of up to date and real-time data. apparently, many troubles associated with control floor among neighborhood contractors even in developing nations. The issues normally range in nature and depth but are typically associated with the inefficient control of construction sources such as substances, labor, plant and subcontractors.

\section{Data Collection on Materials and Labours}

Materials and labors are like a charge bond. These two resources are most crucial resources for the undertaking. Extra than $70 \%$ of the task relies upon these resources which might be well used and utilized.

\subsection{Activity Resource Estimating}

Each schedule activities devour assets and the want for sources ought to be quantified previous the execution of those activities. The quantity and the styles of sources required for activities are estimated in this step.

\subsection{Activity Duration Estimating}

This Activity requires statistics regarding scope of Activity, required aid sorts, anticipated useful resource quantities, and aid calendars. Activity length estimation manner approximate the wide variety of labor periods (Activity duration) required to complete the Activity from facts concerning amount of work effort required to complete the pastime and amount of sources to be applied on that Activity.

\subsection{Schedule Development}

Time table development is the technique of studying activity sequences, durations, useful resource requirements, and agenda constraints to create the undertaking schedule. Time table improvement procedure might also require review and revision of activities duration estimates and useful resource estimates to optimize tradeoff among time, cost and resources. It gives baseline to tune development. To be able to preserve sensible agenda it's miles revised and reviewed constantly because the Project progresses.

\subsection{Schedule Control}

Schedule Control is the process of monitoring the fame of the venture to update mission development and manage adjustments to the time table baseline. This manner offers with, figuring out the status of project schedule, determining various factors that purpose modifications, and managing modifications.

\subsection{Simulation Based Scheduling}

Notwithstanding the essential importance of project completion timeliness, scheduling practices mentioned above continue to be inadequate for addressing the chronic trouble of challenge of completion delays due to inherent uncertainties. With a purpose to contain uncertainty in project activity estimates diverse simulation strategies have been evolved.

\subsection{Materials}

A extensive variety of building materials is to be had for the construction of rural buildings and structures. The proper selection of substances for use in a particular constructing or shape can influence the original cost, maintenance, ease of cleaning, durability and, of course, appearance. 


\section{Data Integration and Data Collection}

Within the pursuit of efficient project performance, time manipulate is one of the most critical functions. It's far greater crucial in big scale and megaprojects; where various threat variables reason agenda delays. For this reason, there are various time management techniques and software programs used for venture planning and scheduling worldwide. Every of the strategies has special features and manner in presenting a list of dates on which sure items are to be completed. Following sections give an explanation for all the associated strategies/techniques and to be had software program packages used for time management.

\subsection{Time Management Techniques/Methods}

Time control is one of the keys to effective mission control as weaknesses within the time manage will reason delays in undertaking of entirety. Consequently, time in creation initiatives need to be controlled from the beginning of the development technique until the venture is absolutely finished.

- Gantt Bar Chart

- Critical Path Networks/Method

- Milestone Date Programming Techniques

\section{Analysis Results}

\subsection{MS-Project}

Fig. 2 shows the Schedule entry in MS-Project.

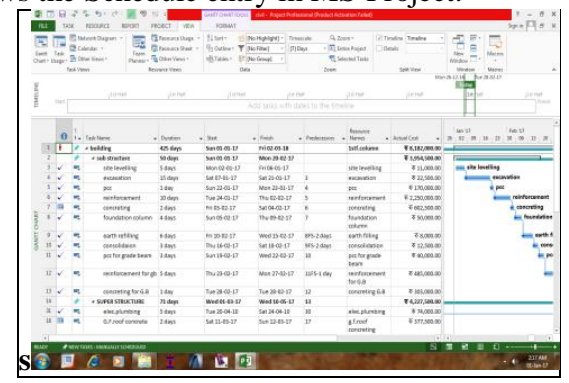

Fig.2: Schedule entry in MS-Project

Fig. 3 shows the flow chart in MSP.

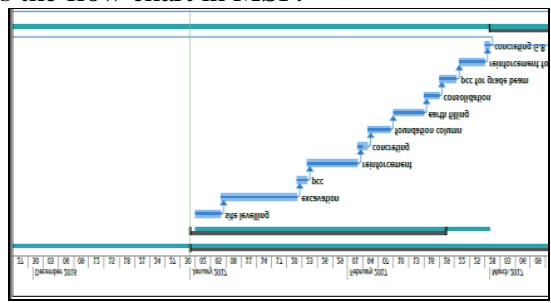

Fig.3: Flow chart in MSP

Fig.4 shows the resources assignment.

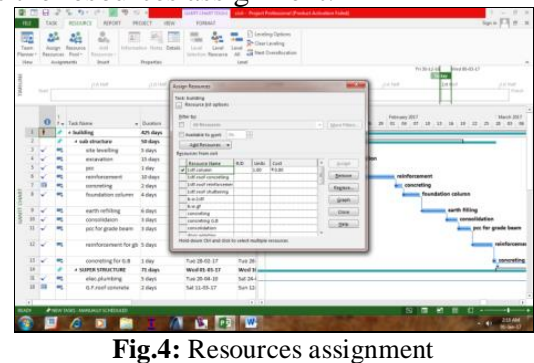

Fig.4: Resources assignment

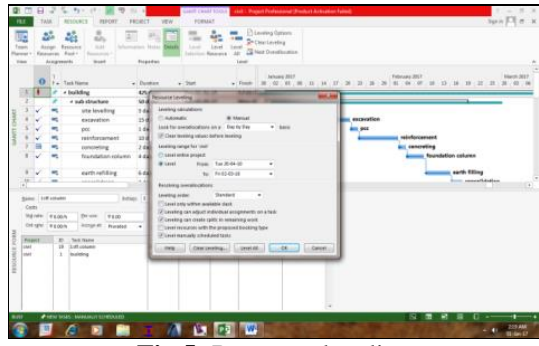

Fig.5: Resource leveling

Fig.6 shows the task assigning

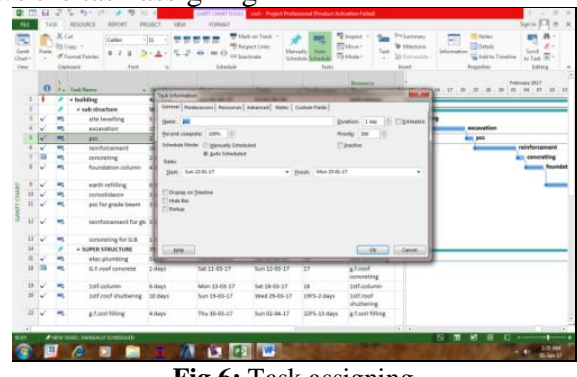

Fig.6: Task assigning

Fig.7 shows the activities assignment

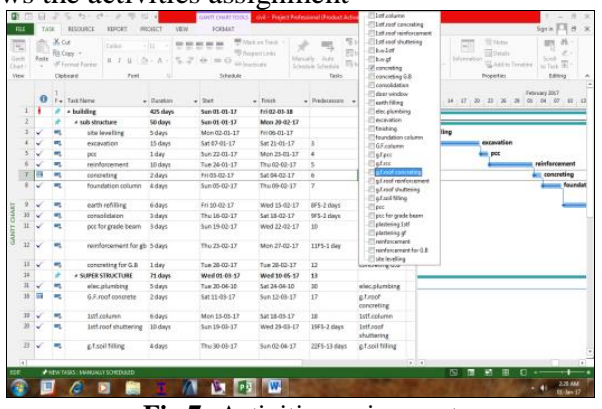

Fig.7: Activities assignment

Fig. 8 shows the cost analysis.

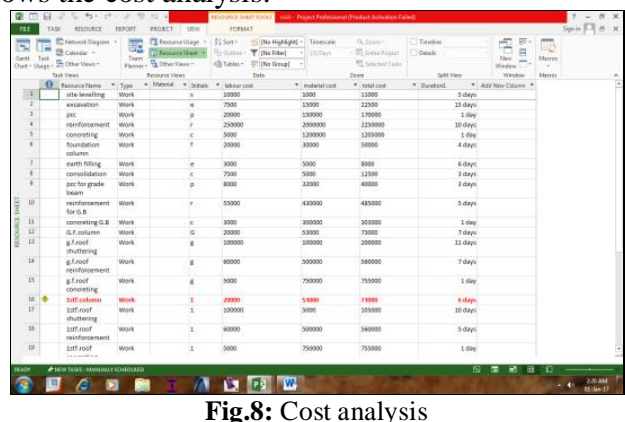

Fig.9 shows the overall cash flow.

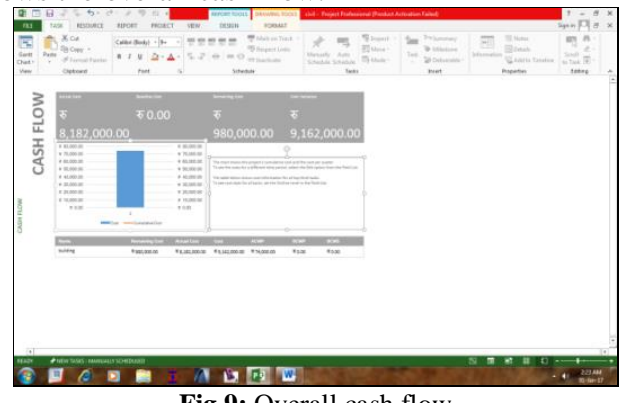

Fig.9: Overall cash flow

Fig.10 shows the cost overrun.

Fig.5 shows the resource leveling. 


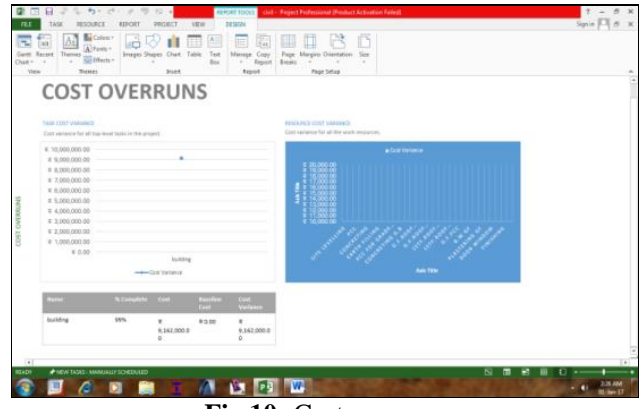

Fig.10: Cost over run

Fig.11 shows the resource over view.

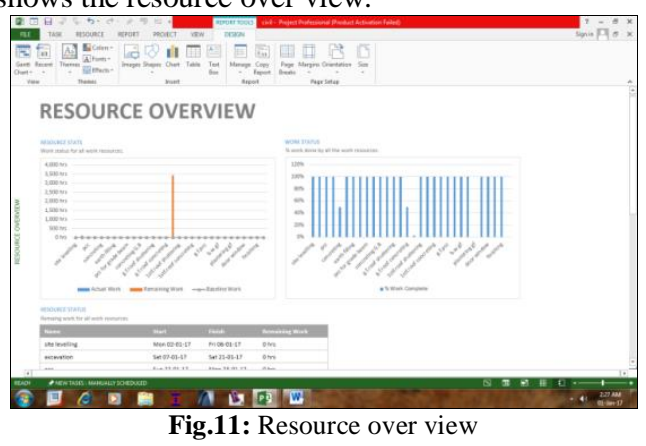

\section{Conclusion}

This total study was carried out to have an overall schedule of the project and find the optimized use of all resources to complete the project. Comprehensive study made in the project about the scheduling, monitoring, and optimization of various construction activities and to use software Microsoft project. The study concluded that effective method of time managements perceived by the respondents was Critical Path Method (CPM).

\section{References}

[1]. T.Subramani., "Cost Estimation and Identification of Transport Infrastructure facility Projects in Salem", International Journal of Engineering and Technology, Vol.2, No.5, Pp 859 - 867,2012.

[2]. T.Subramani., P.Anitha., S.Sekar., "Health-Care Waste Management System", International Journal of Engineering Research and Applications, Vol. 4, Issue 6( Version 2), pp.255-258, 2014.

[3]. T.Subramani., N.Kanthasamy., "High End Solution For Advanced Civil Engineering Projects", International Journal of Modern Engineering Research, Volume. 4, Issue. 6 (Version 3), pp 49-53, 2014.

[4]. T.Subramani.,D.S.StephanJabasingh,J.Jayalakshmi. "Analysis Of Cost Controlling In Construction Industries By Earned Value Method Using Primavera", International Journal of Engineering Research and Applications, Volume. 4, Issue. 6 (Version 5), pp 145 $-153,2014$.

[5]. T.Subramani.T, P.T. Lishitha., M.Kavitha., "Time Overrun And Cost Effectiveness In The Construction Industry", International Journal of Engineering Research and Applications, Volume. 4, Issue. 6 (Version 5), pp 111- 116, 2014.

[6]. T.Subramani. , R.Lordsonmillar., "Safety Management Analysis In Construction Industry", International Journal of Engineering Research and Applications, Volume. 4, Issue. 6 (Version 5), pp 117- 120, 2014.

[7]. T.Subramani., A.Sarkunam.A, J.Jayalakshmi. "Planning And Scheduling Of High Rise Building Using Primavera", International Journal of Engineering Research and Applications, Volume. 4 Issue. 6 (Version 5), pp 134 - 144, 2014.

[8]. T.Subramani.,P.S.Sruthi., M.Kavitha. "Causes Of Cost Overrun In Construction", IOSR Journal of Engineering, Volume. 4, Issue. 6 (Version 3), pp 1 - 7, 2014

[9]. T.Subramani, M.Sekar, " Preplanning And Scheduling Of Road Construction By Using PPM" , International Journal of Application or Innovation in Engineering \& Management (IJAIEM), Volume 4, Issue 5, pp. 234-244, 2015

[10]. T.Subramani, V.Jayaraman , " Analysis Of Construction Worker Migrate From Industries" , International Journal of Application or Innovation in Engineering \& Management (IJAIEM) , Volume 4 Issue 5, pp. 274-283, 2015

[11]. T.Subramani, S.Tamizhanban , " Supply Chain Management In Construction Site By Using SPSS Software" , International Journal of Emerging Trends \& Technology in Computer Science (IJETTCS), Volume 5, Issue 3, pp. 182-193, 2016.

[12]. T.Subramani, S.R.Rajiv , " Improving Construction Efficiency And Productivity Of Industry Using SPSS" , International Journal of Application or Innovation in Engineering \& Management (IJAIEM) , Volume 5, Issue 5, pp. 239-250, 2016

[13]. T.Subramani, K.Chinnadurai , "Construction Management And Scheduling Of Residential Building Using Primavera" International Journal of Application or Innovation in Engineering \& Management (IJAIEM) , Volume 4, Issue 5, pp. 188-198 , 2015

[14]. T.Subramani, Kurian Jacob , " Analysis Of Risk, Threshold And Issues And Monitoring Schedule Of Building Construction Using PPM Software" , International Journal of Emerging Trends \& Technology in Computer Science (IJETTCS), Volume 5, Issue 3, pp. 171-181, 2016

[15]. T.Subramani, M. Muhammed Ansar, S.Priyanka , " Impact Of Prefabricated Technology And Equipment On The Profitability Using Primavera " , International Journal of Emerging Trends \& Technology in Computer Science (IJETTCS), Volume 6, Issue 3, May - June 2017, pp. 176-185 , ISSN 2278-6856.

[16]. T.Subramani, V.Annamalai , S.Priyanka , " Management Information And Communication Technology In Construction Engineering Of Structures Using Primavera " , International Journal of Emerging Trends \& Technology in Computer Science (IJETTCS), Volume 6, Issue 3, May - June 2017 , pp. 186-197, ISSN 2278-6856.

[17]. T.Subramani, V.Bhaskaran Nair, A.David, B.Mohamed Ghouse, N.Siva Kumar , " A Study Of Inventory Management System In Construction Industry " , International Journal of Application or Innovation in Engineering \& Management (IJAIEM), Volume 6 , Issue 5, May 2017 , pp. 304-311, ISSN 2319 - 4847. 